\title{
ANALISIS PERBANDINGAN SISTEM TRADISIONAL DENGAN SISTEM ACTIVITY BASED COSTING DALAM PERHITUNGAN HARGA POKOK PRODUKSI DI PT. PINDAD (PERSERO)
}

\author{
Oleh: \\ Silviana Agustami \\ (Program Studi Akuntasi FPEB Universitas Pendidikan Indonesia) \\ Dedi Irawan \\ (Program Studi Akuntasi FPEB Universitas Pendidikan Indonesia)
}

\begin{abstract}
Calculation of cost of good manufactured (COGM) is amount of all cost production used for processing raw materials into finished good in current period. Uncorrect calculation of COGM will give unfavorable effects for the company, because COGM has a function as basis for deciding the price and profit. This research used descriptive comparative design, which compares two variabels (Traditional System and Activity Based Costing [ABC]). Nazir (2004) mentioned that descriptive research makes sistematically ilustration about the observing phenomena. According to Sugiyono (2002), comparative research is a research that comparing two or more variable. Researcher did this research at PT. Pindad, Jl. Jend. Gatot Subroto 517 Bandung. PT. Pindad uses traditional system to calculate COGM, that is the reason for researcher to do this research. The research did from 2013, December untul 2014, January. The result of this research shows difference between traditional system and ABC system; COGM average of traditional system is lower than the ABC system. It means that COGM calculate uses $A B C$ system give higher value than uses traditional system though the difference value was not too far.
\end{abstract}

Keywords: Traditional System; Activity Based Costing; Cost of Good Manufactured

\section{Pendahuluan}

Garrison et al. (2006:442) yaitu "dalam akuntansi tradisional semua biaya dibebankan ke produk bahkan biaya produksi yang tidak disebabkan oleh produk". Sebagai contoh, sebagian upah untuk keamanan pabrik akan dilokasikan ke produk meskipun upah penjaga keamanan tersebut sama sekali tidak terpengaruh apakah perusahaan berproduksi atau tidak. Hal ini akan sangat merugikan perusahaan khususnya perusahaan manufaktur yang mengerjakan berbagai jenis produk yang berbeda-beda. Alokasi biaya dengan sistem ini mengakibatkan penyimpangan karena tiap produk tidak mengkonsumsi biaya overhead secara proporsional terhadap unit yang diproduksi. Sistem biaya yang biasanya dilakukan adalah sistem tradisional, namun sistem tradisional ini terkadang memberikan distorsi dalam perhitungan biaya. 
Blocher (2000:117) menyebutkan "sistem tradisional adalah sistem penentuan Harga Pokok Produksi dengan mengukur sumber daya yang dikonsumsi dalam proporsi yang sesuai dengan jumlah produk yang dihasilkan". Wijayanti (2011) menyatakan bahwa dalam "sistem tradisional hanya menggunakan driver-driver aktivitas berlevel unit untuk membebankan biaya overhead pabrik pada produk". Driver aktivitas berlevel unit adalah faktor-faktor yang menyebabkan perubahan biaya sesuai dengan perubahan unit produk yang diproduksi.

Menurut Garrison dan Noreen (2006:449) ada dua tahap yang ditempuh dalam perhitungan biaya overhead sistem tradisional, yaitu: "pada sistem tradisional mengalokasikan Biaya Overhead Pabrik ditempuh dengan dua tahap. Pertama, Biaya Overhead Pabrik dibebankan ke unit organisasi (pabrik atau departemen). Kedua, Biaya Overhead Pabrik dibebankan ke masing-masing produk. Elemen-elemen biaya dialokasikan secara proporsional dengan suatu pembanding yang sesuai. Elemen-elemen biaya dialokasikan secara langsung sesuai dengan perhitungannya. Elemen-elemen biaya tersebut dijumlahkan untuk memperoleh nilai Harga Pokok Produksi kemudian dihitung Harga Pokok Produksi untuk setiap produk yang dihasilkan".

Untuk mengatasi masalah di atas maka perusahaan harus mengambil tindakan yang tepat dalam proses perhitungan harga pokok produksi (HPP), maka perlu dilakukan strategi yang sesuai dengan perusahaan. Strategi yang dapat dilakukan salah satunya adalah menganalisis biaya-biaya berdasarkan aktivitas yang mendukung dalam menghasilkan suatu produk, dan menghilangkan biayabiaya dari aktivitas yang tidak memberikan nilai tambah bagi produk. Hal ini disebut dengan Activity Based Costing (ABC).

\section{Kajian Pustaka}

Frank (2008) menyebutkan bahwa "sistem ABC menetapkan biaya-biaya pada aktivitas dalam proses produksi dan kemudian kepada barang atau jasa yang diproduksi berdasarkan pada seberapa banyak barang atau jasa tersebut menggunakan aktivitas untuk memproduksi barang atau jasa tersebut". Kemudian Frank (2008) juga menyebutkan bahwa "sistem ABC menetapkan biaya-biaya pada aktivitas dalam proses produksi dan kemudian kepada barang atau jasa yang diproduksi berdasarkan pada seberapa banyak barang atau jasa tersebut menggunakan aktivitas untuk memproduksi barang atau jasa tersebut".

Mohamed, dkk., (2011) menyebutkan bahwa "ABC system is also established to provide accurate information on the cost of resource demands by individual products, services, and customers, calculating first indirect and support expenses of activities and processes and then expenses of products, services and customers". Pernyataan tersebut berarti bahwa sistem ABC memberikan informasi yang akurat dari biaya dengan menghitung biaya langsung dan tidak langsung. "ABC is a costing system assigns the cost of each activity along with resources to all products and services in each stage of production, marketing, sales process and delivery" (Yanren, 2008). Pernyataan tersebut menerangkan bahwa sistem ABC merupakan sistem perhitungan biaya masingmasing aktivitas untuk menghasilkan barang atau jasa.

"Dengan menggunakan sistem ABC perusahaan dapat mengklasifikasikan aktivitas yang memberikan nilai tambah dan yang tidak memberikan nilai tambah. 
Dengan demikian nilai yang tidak bernilai tambah dapat dihilangkan untuk meningkatkan kinerja" (Akyol, 2005). Frank (2008) juga menyatakan bahwa salah satu manfaat dari menggunakan sistem $\mathrm{ABC}$, yaitu "These benefits included identifying the "true cost" of each manufacturing entity". Berarti bahwa ABC memberikan informasi biaya yang lebih akurat.

Beberapa perbandingan antara sistem biaya tradisional dan sistem biaya Activity Based Costing (ABC) yang dikemukakan oleh Amin Widjaya (1992) adalah sebagai berikut :

a. Sistem biaya $A B C$ menggunakan aktivitas-aktivitas sebagai pemacu biaya (cost driver) untuk menentukan seberapa besar konsumsi overhead dari setiapn produk. Sedangkan sistem biaya tradisional mengalokasikan biaya overhead secara arbitrer berdasarkan satu atau dua basis alokasi yang non reprersentatif.

b. Sistem biaya ABC memfokuskan pada biaya, mutu dan faktor waktu. Sistem biaya tradisional terfokus pada performansi keuangan jangka pendek seperti laba. Apabila sistem biaya tradisional digunakan untuk penentuan harga dan profitabilitas produk, angka-angkanya tidak dapat diandalkan.

c. Sistem biaya ABC memerlukan masukan dari seluruh departemen persyaratan ini mengarah ke integrasi organisasi yang lebih baik dan memberikan suatu pandangan fungsional silang mengenai organisasi.

Sistem biaya ABC mempunyai kebutuhan yang jauh lebih kecil untuk analisis varian dari pada sistem tradisional, karena kelompok biaya (cost pools) dan pemacu biaya (cost driver) jauh lebih akurat dan jelas, selain itu ABC dapat menggunakan data biaya historis pada akhir periode untuk menghilang biaya aktual apabila kebutuhan muncul.

Penelitian ini berfokus pada perbandingan metode tradisional dan activity based costing $(A B C)$ dalam perhitungan harga pokok produksi.

\section{Metode Penelitian}

Metode dalam penelitian ini termasuk deskriptif komparatif. Nazir (2004:54) juga menyatakan bahwa "penelitian komparatif adalah metode penelitian yang ingin menemukan jawaban yang mendasar tentang sebab-akibat dengan menganalisis faktor-faktor terjadinya atau munculnya fenomena tertentu". Sedangkan menurut Sugiyono (2002:11) "penelitian komparatif adalah suatu penelitian yang bersifat membandingkan". Dalam hal ini variabel penelitian masih sama dengan variabel mandiri, tetapi untuk sampelnya digunakan lebih dari satu atau dalam waktu yang berbeda.

Populasi pada penelitian ini adalah laporan biaya produksi departemen marine equipment (ME) PT. PINDAD (Persero) tahun 2012. Sedangkan sampel yang digunakan dalam penelitian ini adalah rincian biaya produksi untuk produk yang termasuk departemen produk alat dan peralatan kapal laut atau marine equipment (ME).

Langkah pertama yang dilakukan adalah mengumpulkan data yang diperlukan, data yang diperoleh melalui teknik pengumpulan data tersebut di atas merupakan data mentah yang memerlukan pengolahan lebih lanjut. Hal ini dimaksudkan agar diperoleh gambaran yang lebih jelas guna memecahkan masalah yang diteliti sehingga memudahkan penulis untuk menjawab pertanyaan penelitian yang telah dikemukakan serta menarik kesimpulan mengenai masalah 
yang akan diteliti. setelah semua data terkumpul dilakukan analisis terhadap data yang telah ada. Analisis ini dilakukan untuk mendapatkan informasi bagi pihakpihak yang berkepentingan. Adapaun analisis data diarahkan pada pengujian tujuan penelitian yang telah diajukan.

Tahapan analisis data dalam penelitian ini dilakukan sebagai berikut:

1. Mendapatkan laporan biaya produksi selama periode penelitian. Data ini terdiri dari data biaya bahan baku, biaya tenaga kerja dan biaya overhead pabrik yang dikeluarkan terkait dengan produk marine equipment (ME) selama periode tahun 2012.

2. Mendapatkan laporan harga pokok produksi dari departemen ME. Data ini merupakan data harga pokok produksi yang dihitung dengan sistem tradisional.

3. Menganalisis aktivitas-aktivitas yang terjadi di dalam proses produksi departemen ME agar membantu peneliti melakukan perhitungan harga pokok produksi dengan sistem $\mathrm{ABC}$.

4. Melakukan perhitungan dan simulasi biaya produksi atau harga pokok produksi (HPP) dengan menggunakan sistem activity based costing. Dalam tahap ini peneliti melakukan pengalokasian biaya overhead yang terjadi dengan cara:

a. Mengelompokkan aktivitas dan biaya yang homogen ke dalam cost pool.

b. Menentukan cost driver untuk setiap cost pool.

c. Menghitung tarif setiap cost pool berdasarkan cost driver yang telah ditentukan dengan cara:

Tabel 1

Tarif Biaya Overhead

\begin{tabular}{|ll|}
\hline Tarif cost pool $1=$ & Total biaya overhead \\
\cline { 2 - 2 } & Cost driver 1 \\
\hline Tarif cost pool $2=$ & Total biaya overhead \\
\hline Cost driver 2 \\
\hline
\end{tabular}

d. Menghitung biaya masing-masing aktivitas dengan cara mengalikan tarif biaya overhead dengan cost driver masing-masing aktivitasnya. Langkah ini dapat digambarkan dengan tabel sebagai berikut:

\section{Tabel 2}

Biaya Overhead Pabrik Produk

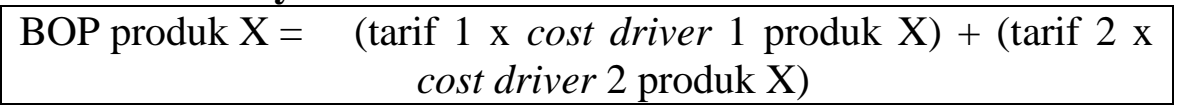

5.Melakukan analisis perbandingan antara perhitungan HPP dengan menggunakan sistem tradisional dan sistem activity based costing (ABC). Dengan cara menghitung rata-rata biaya overhead dari masing-masing sistem tersebut, sebagai berikut:

$$
\bar{x}_{1}=\frac{\sum x_{1}}{n_{1}}
$$




$$
\begin{aligned}
& \bar{x}_{2}=\frac{\sum x_{2}}{n_{2}} \\
& \text { Dimana }: \bar{x}_{1} \quad=\text { rata-rata harga pokok produksi sistem tradisional } \\
& \bar{x}_{2} \quad=\text { rata-rata harga pokok produksi sistem } \mathrm{ABC} \\
& \sum x_{1}=\text { total harga pokok produksi sistem tradisional } \\
& \sum x_{2}=\text { total harga pokok produksi sistem } \mathrm{ABC} \\
& n_{1} \quad=\text { jumlah sampel produk sistem tradisional } \\
& n_{2} \quad=\text { jumlah sampel produk sistem ABC }
\end{aligned}
$$

6.Membandingkan dan menarik kesimpulan dari hasil perbandingan kedua sistem tersebut.

\section{Hasil dan Pembahasan}

Setelah melakukan wawancara dan observasi pada departemen marine equipment peneliti memperoleh data dan informasi-informasi yang dibutuhkan dalam penyusunan skripsi yang berkaitan dengan biaya produksi. Dari laporan produksi departemen marine equipment PT. Pindad (Persero) tahun 2012 yang didapatkan, maka peneliti menentukan sampel penelitian sebagai berikut:

Tabel 3

Sampel Produk Sistem ABC

\begin{tabular}{|c|l|}
\hline NO & \multicolumn{1}{|c|}{ PRODUK } \\
\hline 1 & Hydraulic Comb. Windlass \\
\hline 2 & Hydraulic Mooring winch \\
\hline 3 & Powerpack for comb. Windlass \\
\hline 4 & Powerpack for mooring winch \\
\hline 5 & Hydraulic Steering gear \\
\hline 6 & Cargo hoce handling crane \\
\hline 7 & Accommodation ladder \\
\hline 8 & Provission crane \\
\hline 9 & Spare part crane \\
\hline 10 & Hydraulic Double Windlass \\
\hline 11 & Chain Stopper \\
\hline 12 & Towing hook \\
\hline
\end{tabular}


Untuk mengetahui perbandingan biaya produksi atau harga pokok produksi (HPP) sistem tradisional dengan sistem $\mathrm{ABC}$, terlebih dahulu dicari ratarata tiap variabel yang diuji, rata-rata masing-masing variabel dihitung dengan rumus sebagai berikut :

$$
\overline{\mathrm{X}}_{1}=\frac{\Sigma \mathrm{X}_{1}}{\mathrm{n}_{1}} \quad \overline{\mathrm{X}}_{2}=\frac{\Sigma \mathrm{X}_{2}}{\mathrm{n}_{2}}
$$

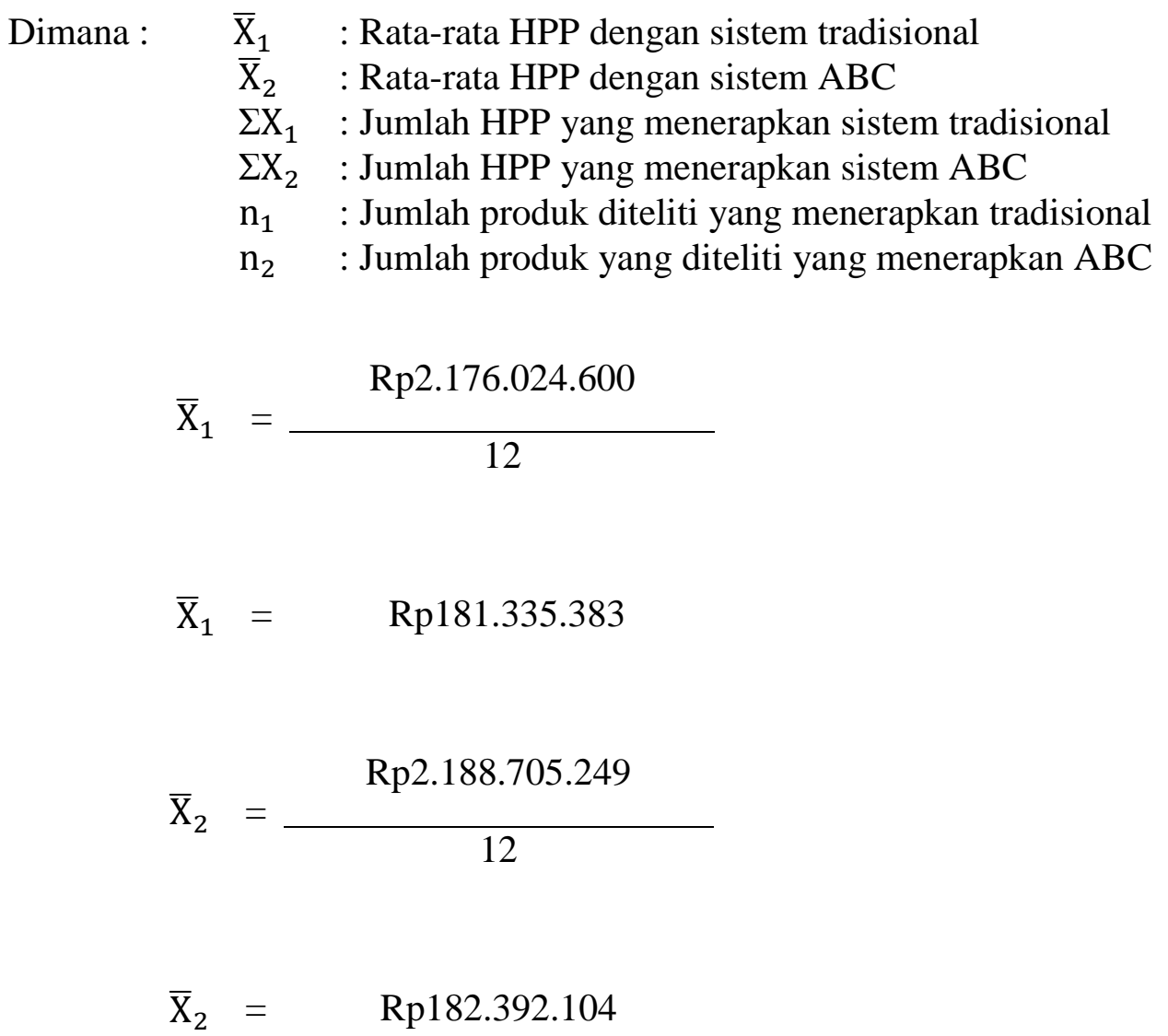

Bila dibandingkan menurut perhitungan di atas ada perbedaan antara harga pokok produksi sistem tradisional dengan harga pokok produksi dengan menggunakan sistem ABC. Harga pokok produksi sistem tradisional undercost sebesar Rp. 1.056.721 dari sistem ABC, ini berarti bahwa harga pokok produksi dengan sistem $\mathrm{ABC}$ memberikan nilai yang lebih tinggi dibandingkan dengan harga pokok produksi sistem tradisional walaupun perbedaannya tidak terlalu jauh.

Tingginya rata-rata harga pokok produksi sistem ABC daripada sistem tradisional menunjukkan bahwa dari sisi besaran biaya yang dikonsumsi dalam proses produksi sistem $\mathrm{ABC}$ menghabiskan biaya yang lebih tinggi dibandingkan sistem tradisional pada departemen marine equipment (ME) PT. Pindad (Persero) tahun 2012. Dapat dikatakan bahwa departemen ME PT. Pindad lebih sesuai menggunakan sistem tradisional dalam perhitungan biaya produksi atau harga pokok produksinya. 
Hasil penelitian di atas sejalan dengan penelitian Rahmat (2009) menyebutkan bahwa tidak terdapat perbedaan yang signifikan dalam perhitungan alokasi biaya overhead pabrik dengan dengan sistem konvensional dan sistem ABC. Hal yang sejalan adalah sistem ABC tidak memberikan hasil yang lebih baik secara besaran biaya yang dikonsumsi. Hasil penelitian ini juga sejalan dengan penelitian yang dilakukan oleh Innes dan Mitchell (1997) yang menyebutkan bahwa sistem ABC dianggap belum memberikan fakta empiris yang menunjukkan bahwa kinerja organisasi akan menjadi lebih baik setelah mengimplementasi sistem ini.

Riset Ho dan Kidwell (2000) menunjukkan temuan yang sama, ternyata dinegara asalnya $\mathrm{ABC}$ bukan alat manajemen yang paling diminati oleh para manajer. Dari hasil penelitian tersebut justru benchmarking dan rekayasa proses dianggap sebagai alat yang paling tepat untuk berbagai pengambilan keputusan strategis. Terjadinya overcosting dan undercosting pada perhitungan harga pokok produksi dengan kedua sistem tersebut menunjukkan bahwa adanya perbedaan yang mendasar dari kedua sistem tersebut yaitu sistem tradisional dan sistem ABC. selama melakukan penelitian baik dengan melakukan observasi secara langsung ataupun dengan melakukan wawancara, peneliti menyadari bahwa dengan sistem $\mathrm{ABC}$ asal-usul biaya dapat terlihat jelas dari setiap aktivitas yang dilakukan dalam proses produksi yang dilakukan oleh departemen marine equipment

Dengan mengetahui aktivitas-aktivitas apa saja yang muncul dalam proses produksi yaitu aktivitas mendesain produk, pemotongan bahan, pengecoran, perakitan, pengecekkan, pengerjaan ulang dan pengepakkan. Kita dapat dengan mudah mengetahui aktivitas mana yang memungkinkan bisa dihilangkan. Aktivitas yang mungkin untuk dihilangkan adalah aktivitas mendesain produk. PT. Pindad yang menggunakan metode harga pokok berdasarkan pesanan memungkinkan semua pesanan untuk satu unit produk dengan desain yang sama, dalam arti bahwa satu produk yang dibuat untuk semua pesanan dari konsumen yang berbeda tetap desainnya akan sama. Oleh karena itu aktivitas mendesain produk sebenarnya memungkinkan untuk dihilangkan dan tentunya akan mengurangi biaya yang dikeluarkan.

\section{Simpulan}

Dari penelitian mengenai Analisis Perbandingan antara Sistem Tradisional dengan Sistem Activity Based Costing dalam Perhitungan Harga Pokok Produksi di PT. PINDAD (persero) Divisi mesin industri dan jasa departemen produk alat dan peralatan kapal laut atau departemen marine equipment (ME) tahun 2012, maka dapat diambil kesimpulan sebagai berikut:

1. Penerapan sistem kalkulasi biaya pada setiap perusahaan akan berbeda-beda, pemilihan sistem yang sesuai bagi perusahaan serta mampu memenuhi kebutuhan dan memberikan manfaat bagi perusahaan menjadi syarat yang harus dipenuhi. Penerapan sistem tradisional pada Departemen marine equipment PT. Pindad selama ini dapat dikatakan memberi informasi yang memadai bagi perusahaan mengenai perhitungan biaya produksi.

2. Sistem Activity Based Costing memberikan informasi yang lebih akurat serta mampu menunjukkan asal-usul biaya yang dikonsumsi pada proses produksi. Karena biaya yang muncul merupakan biaya yang berasal dari aktivitas- 
aktivitas yang terjadi pada proses produksi serta memungkinkan bagi manajemen untuk menganalisis aktivitas-aktivitas yang seharusnya bisa dihilangkan.

3. Perbandingan antara HPP sistem tradisional dengan sistem ABC di PT. Pindad departemen marine equipment tahun 2012 menunjukkan perbedaan bahwa rata-rata HPP berdasarkan sistem ABC lebih besar dibandingkan dengan sistem tradisional yang telah digunakan. Penelitian ini menggambarkan bahwa sistem tradisional yang telah digunakan lebih dahulu memberikan nilai atau jumlah biaya produksi yang lebih rendah jika dibandingkan dengan jumlah biaya yang muncul menggunakan sistem Activity Based

\section{Daftar Pustaka}

Akyol, et. al. (2005). An Analysis of Activity-Based Costing in a Manufacturing System. International Journal of Information and Communication Engineering 1:5.

Amin Widjaja. (1992). Activity Based Costing Suatu Pengantar. Jakarta: Rineka Cipta.

Blocher, dkk. (2000). Manajemen Biaya : dengan Tekanan Stratejik. Jakarta: Penerbit Salemba Empat.

Frank, Minjares. (2008). "Activity-Based Costing at Diebold”. International Journal of Strategic Cost Management / Volume 3, Number 2.

Garrison, Ray H. Eric W Noreen. (2006). Managerial Accounting. Diterjemahkan oleh A. Totok Budisantoso dengan judul Akuntansi Manajerial. Buku 1. Jakarta: Salemba Empat.

Mohamed, et al. (2011). "activity based costing (abc) as an approach to optimize purchasing performance in hospitality industry". international journal of social sciences and humanity studies vol 3, no 2, 2011 issn: 1309-8063.

Moh, Nazir. (2004). Metode Penelitian. Bogor: Ghalia Indonesia.

Sugiyono. (2002). Metode penelitian administrasi. Bandung: CV. Alphabeta.

Wijayanti, Ratna. (2011). Penerapan activity-based costing system untuk menentukan harga pokok produksi pada pt. Industri sandang nusantara unit patal secang. Yogyakarta: skripsi Universitas Negri Yogyakarta.

Yanren X, Wenbin S, Thomas WL. (2008). Activity-Based Costing Popularity in China. Cost. Manage, 22(3): 40-48 